\title{
THE SOCIETY FOR THE SOCIAL HISTORY OF MEDICINE
}

The ANNuAL Conference of the Society was held on 2-4 July 1971 at the University of York. In opening the meeting the President, Dr. Ruth Hodgkinson, indicated the many pioneering activities in the social history of medicine in York and Yorkshire; therefore it was ideal to have the first conference there. The variety of subjects covered demonstrated the wide range of members' interests and work. Every speaker stimulated interesting discussion.

The following papers were presented: Professor K. Jones: 'Moral Management and the Therapeutic Community'; Dr. R. Hunter: 'The Value of the Historical Approach in Clarifying Present Problems'; Professor A. Smith: 'The Development of Numerical Methods in Public Health'; Dr. J. Woodward: 'Blood, Sweat and Tears-British Hospitals in the eighteenth and nineteenth Centuries'; Dr. I. Hindmarch: 'The Social History of Drug Taking'; Professor N. Dewey (U.S.A.): 'Medicine and Society in English Literature; Problems and Methods of Research'.

Lord James, Vice-Chancellor of the University, guest of honour at the Dinner, spoke of the need for such a body as the Society and that, 'if it did not exist it would have been necessary to invent it'.

Those in Great Britain or abroad who are interested in joining the Society should contact the Secretary, Mr. Gordon Wilson, 183 Euston Road, London N.W.1.

\section{A NEW DEPARTMENT OF THE HISTORY OF MEDICINE AT KING'S COLLEGE HOSPITAL MEDICAL SCHOOL}

We hAVE pleasure in announcing that the Council of King's College Hospital Medical School, on the recommendation of its Academic Board, decided in July to institute an independent Department of the History of Medicine. It is to be staffed by Dr. F. F. Cartwright, Dr. W. D. Foster, Dr. Charles James and Miss Pentelow, the librarian of the Medical School. Its purpose is to organize systematic teaching in the history of medicine and to encourage an interest in the subject among both undergraduates and teachers. The School's fine collection of historical texts, as well as important manuscript material, including all the Lister documents, are being placed in the Department's care.

It is of interest to record that all three medical teachers in the new Department have been concerned with the Diploma Course organized by the Faculty of the History of Medicine of the Society of Apothecaries. Both Dr. Cartwright and Dr. Foster have lectured in the course and participated in a number of seminars, while Dr. James was a member of the course and was among the first group to be awarded the Apothecaries' new Diploma in the History of Medicine. 